\title{
Room for Maneuver: Julie Cohen's Theory of Freedom in the Information State
}

\author{
Jack M. Balkin`
}

\section{Introduction: selves and information policy}

Julie Cohen's Configuring the Networked Self ${ }^{1}$ is a book about information policy in the digital age, but its author is after bigger game. Cohen argues that how we look at information policy will differ depending on how we imagine the nature of the self. Throughout the book, Cohen's foil is a set of assumptions about selves in contemporary legal theory, sometimes openly stated, sometimes merely assumed. In this conception, selves are autonomous, independent, and freely choosing. They consciously compose and follow their life plans and they make rational decisions based on a more or less stable set of values and preferences.

Much of the book critiques these and similar assumptions and the way that they subtly structure debates about information policy. For example, Cohen argues that theories of copyright and fair use based on romantic authors and transformative users (or, conversely, on rational maximizers and consumers) can be misleading because much creative activity is not consciously chosen, and much creation is done haphazardly, collectively, or through bricolage. ${ }^{2}$ Similarly she criticizes theories of privacy that view information collection, use and distribution as inherently connected to the promotion and dissemination of truth, and that understand individual dignity to require individualized treatment. ${ }^{3}$ Information collection may lead to exposure and loss of control rather than to the promotion of truth. Individualized treatment, rather than promoting human dignity, may undermine it, for example, through targeted surveillance or customized search. ${ }^{4}$

\footnotetext{
${ }^{\star}$ Knight Professor of Constitutional Law and the First Amendment, Yale Law School. Email: jack.balkin@yale.edu.

${ }^{1}$ Julie E. Cohen, Configuring the Networked Self: Law, Code and the Play of Everyday Practice (2012).

Id. at $80,93-95$.

${ }^{3} \mathrm{Id}$. at $118-19$.

${ }^{4}$ Id. at $248-50$.

(C) The Author 2013. Published by Oxford University Press and the Hebrew University of Jerusalem. All rights reserved. For Permissions, please email: journals.permissions@oup.com
} 
In place of these assumptions, Cohen wants to offer a portrait of selves that are continuously constructed by various features of cultural, political, social, economic, and technological power, selves that are never fully formed, but constantly evolving, selves that are busily trying out new techniques, practices, forms of knowledge and even identities.

In Cohen's portrait, the self is constantly traveling through terrains that themselves are constantly changing. It finds itself thrown into perplexing new circumstances, and continually navigating uncertain opportunities, evolving limits, malleable boundaries, developing conventions, and ever-mutating forms of power. The relationships between selves and others, and their respective identities, are negotiated and renegotiated as people move through their lives. Hence, Cohen offers a vision of the self that is constantly in a process of becoming, like Heraclitus's river-always flowing, but never the same. Armed with this postmodern portrait of the self, Cohen hopes to take on the thorniest issues in information policy, and in particular, privacy and copyright.

\section{Play and semantic discontinuity}

Along with a counter-portrait of selves, Cohen offers a counter-portrait of freedom. Her two big ideas are the play of everyday practice and semantic discontinuity.

Play means trying out new things through the practices of everyday life. One plays not only with objects and conventions, but also with one's identity and one's relationships with others. We should understand selves, Cohen argues, as situated within changing cultural contexts, technological structures, authorizations, and forms of power, and changing in response to these changes.

Selves continually engage in play, which involves experimentation, testing, and revising, not necessarily with a clearly defined goal. Many purposes and reasons for behavior are emergent, arising out of situations and actions. People's identities are not completely stable, but shift as they are placed in new social contexts, and change over time. Selves constantly evolve, whether by design or accident. In this way, the play of everyday practice has feedback effects on self-understanding and identity.

Cohen argues that good information policy should take these features of human experience into account. Copyright policy should recognize the importance of play in human action. It should leave ample room for experimentation, mixture, and bricolage, especially with respect to noncommercial uses. Similarly, privacy policy should recognize that people have multiple identities, and that their selves are always in the process of being formed. People need space to experiment and try out new practices and personas. Privacy policy should permit people to engage in boundary maintenance and to configure and reconfigure their relationships with others; through this process people's selves and their identities will change. In the Internet age, Cohen informs us, human 
freedom means room for maneuver in increasingly intricate systems of informational control.

Protecting the play of everyday practice may also require special rules for intermediaries and software platforms that can facilitate and protect play. Hence, we might offer immunities or safe harbor rules for intermediaries and platforms not for their own sake but because of their role in fostering the play of everyday practice.

Cohen's vision of human freedom emphasizes three key ideas. First, people must enjoy access to knowledge - meaningful access to informational and cultural resources - as a requirement of human flourishing. "Without the raw materials necessary for social and cultural participation," Cohen argues, "one cannot participate meaningfully in the development of culture and community, and without access to the appropriate networks and tools, one cannot partake of the resources that the networked information society has to offer." ${ }^{5}$

Second, people must have operational transparency. This means that people must know how they are situated in code and technologies, what is being done to them, how code and technology limit their actions and choices and why. ${ }^{6}$

The third idea, and the most important, is semantic discontinuity: "gaps and inconsistencies within systems of meaning and... a resulting interstitial complexity that leaves room for the play of everyday practice."7 Although Cohen initially states this idea in terms of meanings, it soon becomes clear that she is talking about gaps in enforcement and in systems of surveillance and control. That is because systems of meaning in a networked environment are also systems of control and surveillance. (Think of collection and collation of personal data, or digital rights management as examples.) Therefore, "semantic discontinuity" means "interstitial flexibility within the system of legal rights, institutional arrangements, and associated technical controls." 8 Semantic discontinuity means discontinuity in forms of social and technical power. It "is the opposite of seamlessness: it is a function of interstitial complexity within the institutional and technical frameworks that define information rights and obligations and establish protocols for information collection, storage, processing, and exchange." 9

In the analog world, there are many gaps, flexibilities, and inconsistencies in social conventions, in the protection of rights, or in law enforcement. The analog world is a world of pervasive discontinuity and improvisation, even though we do not always notice it. And when called to our attention, we may see these aspects of our lives as limitations and imperfections-as bugs rather than as features. Yet, Cohen insists they may actually be good for us,

\footnotetext{
${ }^{5}$ Id. at 224 .

${ }^{6}$ Id. at $224,234-35$.

${ }^{7} \mathrm{Id}$. at 224 .

${ }^{8} I d$. at 234 .

${ }^{9}$ Id. at 239 .
} 
because they give us space for improvisation and, more generally, freedom. As we move to an increasingly automated, networked world, these gaps and discontinuities may be displaced or eliminated. Governments, businesses, and other institutions have incentives to build systems that track and collate more and more forms of potential information and that increasingly use technology to enforce rules and norms. The gaps, discontinuities, fudges-and therefore opportunities - that we take for granted in our analog world are slowly being eliminated in favor of a more precise, regulated, and watched-over existence. As more and more of our lives either occur on information networks or are accessible to them, more and more can be known about everyday life, and systems of control can increasingly pervade everyday life.

This sounds a lot like Michel Foucault's idea of modern societies as disciplinary societies, and his notion of power in modern societies existing everywhere. But Cohen's actual inspiration seems to be the work of Gilles Deleuze and Felix Guattari, and their idea of "surveillant assemblages"- "a heterogeneous, linked set of processes and techniques that seeks to harness the raw power of information by fixing flows of information cognitively and spatially." 10 What networked citizens need, Cohen, argues, is an "interstitial complexity that leaves room for the play of everyday practice. In an increasingly networked information society, maintaining those gaps requires interventions designed to counterbalance the forces that seek to close them." 11

In 1980, Bruce Ackerman dreamed of a "perfect technology of justice" that would automatically and perfectly secure people's justified rights. ${ }^{12}$ In this conception, injustice arises from imperfect technology, imperfect information, and imperfect enforcement. Officials may lack correct or sufficient knowledge; they may have irrational prejudices; resource constraints may cause them to cut corners, and so on. A perfect technology of justice would eliminate these problems, maximize knowledge, and secure automatic protection of rights, thus ensuring just results.

Cohen's idea of semantic discontinuity begins with the opposite assumption. We build systems to achieve certain ends, like social order, national security, or property protection. These systems are a complicated amalgam of practices, norms, and technologies for identification of law breaking, prosecution, and punishment. As those practices, norms, and technologies become increasingly powerful and pervasive, they may do more than protect our rights; they may actually decrease our practical freedom. An imperfect system of control, rather than being a hindrance to human liberty, may sometimes be necessary to it,

\footnotetext{
${ }^{10} \mathrm{Id}$. at 137 .

${ }^{11} \mathrm{Id}$. at 224 .

12 Bruce A. Ackerman, Social Justice in the Liberal State 21 (1980) ("So long as you and I can imagine a power structure $P_{i}, \ldots$ the perfect technology of justice will costlessly allow us to shape our relations in the way specified by $P_{i}$.") The point of such a technology was designed to show how many criticisms of liberalism stem not from liberalism itself but from our current inability to implement "the ideal of Neutral dialogue under imperfect technological conditions." Id. at 22-23.
} 
even if this means that some laws will go unpunished and some norms will be only imperfectly realized. Cohen's argument for "semantic discontinuity" in networked systems is related to Danielle Citron's call for "technological due process" and Jonathan Zittrain's critique of systems of "perfect enforcement."13

An imperfect system of justice in a realm with a distant king and a limited state apparatus allows people to move and flee prosecution, change identities, and start over, even if it sometimes allows some bad actors to violate the law with impunity. This imperfect system of control offers a kind of freedom, but through imperfection rather than through the direct protection of rights; in fact, we might even think of it as a kind of freedom from the increasing perfection of rational control. To be sure, semantic discontinuity is not anarchyfor it exists only in the interstices of larger systems of enforcement, information collection, and control. Rather, semantic discontinuity refers to pockets or slivers of imperfection distributed within multiple and interpenetrating systems of governance and surveillance.

As the forms of surveillance, governance, and control multiply and overlap in modern societies, the imperfections in these systems become increasingly important because they preserve gaps or fissures that allow room for maneuver and space for improvisation. These gaps or fissures do not have to exist purely by chance; we can accommodate the need for semantic discontinuity through conscious choice. Indeed, Cohen believes, as we design technological systems to achieve particular ends-whether they be national security, efficient delivery of goods and services, or copyright enforcement-we must make sure that these systems have lacunae, ambiguities, and inconsistencies.

Cohen's argument, in short, is that instead of designing seamlessness and perfection into these systems, we should design gaps and incompleteness; or, in the alternative, we should take advantage of imperfections that are already present and use them to preserve a space for the play of everyday practice. In contrast with Ackerman's dream of a perfect technology of justice, Cohen dreams of systems that do not cover everything, that work only partly and up to a point.

Cohen's advocacy of semantic discontinuity is part of a larger tradition of thought about the Internet. To a significant degree, left-libertarian celebrations of the Internet have been premised on a hope that cyberspace might confound existing systems of authority and control, and that the Internet might offer a sort of 21 st century version of a Biblical city of refuge-a place where the disaffected could flee, change identities, or indeed, maintain multiple personae. Liberals and libertarians thus celebrated the Internet as a source of new-found freedom that might escape existing forms of power and authority while worrying that this freedom would not prove lasting. Indeed, Larry Lessig's

\footnotetext{
${ }^{13}$ Danielle Keats Citron, Technological Due Process, 85 Wash. Univ. L. Rev. 1249 (2008); Jonathan Zittrain, The Future of the Internet (And How to Stop it) 107-23 (2008).
} 
pessimistic conclusion in one of the earliest works on cyberlaw, Code And Other Laws of Cyberspace, ${ }^{14}$ was that governments and private businesses would soon reestablish control through code, while in their aptly titled book Who Controls the Internet?: Illusions of a Borderless World, ${ }^{15}$ Jack Goldsmith and Tim Wu argued that nation states could and would increasingly establish control over digital networks in conjunction with private enterprise.

Nevertheless, we must complicate Cohen's theory of semantic discontinuity with several caveats. First, semantic discontinuity might be only a second-best solution to the problem of freedom. Surely one would want at least some rules, technologies, and practices that directly protected individuals from overreaching by powerful public and private entities. Cohen's idea of semantic discontinuity responds to the concern that overlapping forms of technological, economic, social and cultural power will proliferate endlessly, and therefore we need to preserve gaps and discontinuities in which play can thrive. Put differently, Cohen's concept of semantic discontinuity is not a complete account of human freedom, but simply one aspect of freedom in a networked world, along with (for example) other values like access to knowledge and operational transparency.

Second, although I have offered examples taken from criminal law enforcement, Cohen's idea of semantic discontinuity is about private power as well as public power. New systems of surveillance and control are being built by governments, by corporations, and through systems of public-private cooperation. In the area of cybersecurity, it is increasingly difficult to separate the public and private sphere. Data collection presents similar problems: The state often seeks access to privately compiled and organized databases, while private organizations collect data both in their capacity as government contractors and as data brokers for other private organizations.

Both the state and private actors are busily building out systems of prevention, control, and surveillance for various purposes. National security policy seeks more effective ways of identifying threats and nipping them in the bud. Advertisers seek better ways of identifying and analyzing their customers and matching prospective buyers to sellers. Governments seek information about populations not only to govern them but to deliver valuable social services that are among the chief benefits of citizenship in the modern state. Content industries seek better ways of expanding markets, preventing piracy, placing their goods securely in the hands of paying customers, and finding out more about how their customers use these goods. What the state and private enterprise share in common is their quest for perfect technologies-of data collection, analysis, prevention, security, enforcement, and delivery of services.

\footnotetext{
${ }^{14}$ Lawrence Lessig, Code and Other Laws of Cyberspace (1999).

${ }^{15}$ Jack Goldsmith \& Tim Wu, Who Controls the Internet?: Illusions of a Borderless World (2006).
} 
A third caveat follows from the second. Cohen's conception of semantic discontinuity is necessarily asymmetric. She judges the presence or absence of semantic discontinuity from the perspective of a particular individual, and not from the perspective of governments, businesses, or other powerful institutions. This asymmetry is necessary to ensure that discontinuity helps individuals rather than hurts them. Some gaps in legal and technological enforcement might benefit the powerful far more than the powerless. Governments might take advantage of gaps in civil liberties protections; large businesses might take advantage of gaps in consumer protection regulations. Facebook's ever-shifting privacy policies seem to be a prominent example of a business taking full advantage of semantic discontinuities wherever it finds them. But Cohen seeks semantic discontinuity for the benefit of the ordinary individual and not for the Leviathan state, the national security apparatus, the multinational corporation, or the malefactor of great wealth.

Although this asymmetry is theoretically necessary to Cohen's argument, it is not clear whether she can fully justify or operationalize it. Gaps and ambiguities in code and law that benefit individuals might also benefit powerful corporations, and vice versa. Indeed, sometimes it may not be possible to separate the two in practice. Think of Google's current position on fair use as an example. YouTube's business model is premised on incomplete and ineffective enforcement of copyright infringement. For that matter, so is Google's entire enterprise of scraping content from virtually every site on the Web, storing it, indexing it, and serving up parts of it on demand, all without permission of the copyright owner. Here Cohen's notion of semantic discontinuity seems related to Jonathan Zittrain's argument for protecting emerging businesses that foster the generativity of the Internet. ${ }^{16}$

Many of the businesses and intermediaries on which the play of everyday practice depends are themselves the beneficiaries of gaps and ambiguities in the law. It may be difficult if not impossible to create information systems and policies that offer gaps and ambiguities that individuals can exploit without also handing the same tools to large private enterprises-who, after all, have greater access to technical and legal talent to exploit them. Indeed, the problem with ambiguities in a legal system is that the rich may be able to exploit them better than the poor; and the problem with gaps is that the powerful may be able to push through them more easily than the weak. The philosopher Anacharsis once remarked to the great lawgiver Solon that laws are like spider's webs that snare the weak and poor but that the rich and mighty can easily break through. ${ }^{17}$

\footnotetext{
${ }^{16}$ Jonathan Zittrain, The Future of the Internet, at 31-33 (arguing for a "procrastination principle" in Internet design).

171 Plutarch's, Lives 109 (John Dryden trans., Arthur Hugh Clough ed. 2001)
} 
Semantic discontinuity is ultimately about tradeoffs, and Cohen's book only begins the discussion about how those tradeoffs might be accomplished. Even the metaphor of tradeoffs may be misleading, as it suggests a careful balance of benefits and risks. But the whole point of gaps and discontinuities in networked systems is that they offer opportunities for the unexpected, and for unforeseen transformations of power-including ever new opportunities for exercising power over others.

How might we apply semantic discontinuity to information policy? In the context of privacy law, Cohen argues that semantic discontinuity means incomplete collection, limits on collation and use, and requirements of data obsolescence and destruction. Not all data are collected, data that are collected are not fully analyzed, and data that are collected or analyzed are eventually discarded.

With respect to copyright, semantic discontinuity means preserving gaps in the scope and coverage of copyright law, either deliberately or as a result of technological innovations. Semantic discontinuity means incomplete coverage, incomplete protection, and incomplete enforcement. One advantage of older, technologically outmoded copyright laws like the 1909 Copyright Act, Cohen argues, is that property rights were often consciously delimited by formal distinctions and requirements, leaving wide gaps in copyright coverage: "a legal regime characterized by formally incomplete rights - by logical gaps that permit at least some uncontrolled access and use-comes closer to solving the balancing problem that copyright confronts." 18

Copyright owners might see such gaps either as money left on the table or as an invitation to piracy and theft. That is why they have repeatedly pressed for expansion of copyright protection so that it covers every possible use that copyright owners might someday want to exploit. Cohen, in contrast, sees some of these limitations as advantages. Gaps in coverage, protection, and enforcement create opportunities for experimentation by a wide variety of participants, especially as technology evolves. "Creative practice flourishes most fully under conditions that permit unexpected encounters with new information and that provide room for reworking, tinkering, and other forms of creative play." 19 Instead of "broad, all-encompassing statutory provisions and generous, judicially created tests for infringement," the law should offer "narrower, clearly delimited formulations of copyright rights separated by deliberate gaps representing uses that are reserved in the service of cultural play, regardless of commercial consequence." ${ }^{20}$ Thus, in Cohen's view, special copyright rules for libraries, the first sale doctrine, and fair use itself, should not be justified as second-best responses to market imperfections that might someday be eliminated if transaction costs could be sufficiently reduced. Rather, we

\footnotetext{
${ }^{18}$ Cohen, supra note 1 at 246.

${ }^{19} \mathrm{Id}$. at 246.

${ }^{20} \mathrm{Id}$.
} 
should understood these rules as desirable gaps in a system of copyright enforcement that allow people to gain access to knowledge and play with information and culture. ${ }^{21}$

\section{Play, semantic discontinuity and freedom of expression}

Configuring the Networked Self is not specifically about free expression, but the book nevertheless remains quite relevant to it. Cohen's argument, after all, concerns the conditions of cultural freedom in the digital age. Freedom of speech is a central aspect of cultural freedom, not to mention a central concern of any systematic account of knowledge and information policy.

Moreover, the central concerns of the book are (i) privacy, (ii) copyright, and (iii) control over digital networks. Not coincidentally, it turns out that the three key problems of freedom of speech in the digital age are (i) the relationship between freedom of expression and privacy, (ii) the relationship between free expression and copyright, and (iii) control over digital networks (which includes issues like intermediary liability, filtering, blocking, and throttling content).

Thus, much of what Cohen says about these issues can also be understood in terms of free speech values. Limited copyright creates more space for using cultural resources in expression. Although information privacy is sometimes in tension with freedom of speech, freedom of conscience and freedom of association often require anonymity or pseudonymity. Moreover, many kinds of privacy restrictions on data collection and use do not conflict with freedom of expression at all. ${ }^{22}$ Digital controls over networks-for example, government-mandated filtering regimes-clearly raise free speech concerns. Finally, limits on intermediary liability-like section 230 of the 1996 Telecommunications Act-may not be required by the First Amendment, but such doctrines clearly implicate free speech values. ${ }^{23}$

How should we apply Cohen's ideas of a postmodern self, the play of everyday practice and semantic discontinuity to the problems of free expression in the digital age?

At the outset, Cohen's argument poses a challenge to traditional understandings of free expression. Contemporary free speech law seems to be premised on the very sort of self that Cohen argues is a fiction. Free speech law generally ascribes autonomy and independence to individuals in their choices about what to read or not to read. It assumes that adults generally can decide for themselves what expression they wish to encounter. That is why we place

\footnotetext{
${ }^{21}$ Id. at $230-32$.

${ }^{22}$ For examples, see Neil Richards, Reconciling Data Privacy and the First Amendment, 52 UCLA L. Rev. 1149 (2005).

${ }^{23}$ Jack M. Balkin, The Future of Free Expression in a Digital Age, 36 Pepperdine L. Rev. 428 (2009).
} 
responsibility on individuals to decide what to read or not to read, rather than the state, and that is why we tell individuals that if they dislike certain forms of expression, they must avoid them or argue against them rather than have the state censor them. In the words of Justice John Marshall Harlan in Cohen v. California, if autonomous individuals are offended by speech, they always have the choice to avert their eyes. ${ }^{24}$ In contrast, when the law regards individuals as not autonomous, but as dependent, we allow the state to regulate expression. ${ }^{25}$ (The classic example is children.) Cohen challenges the opposition between independence and dependence implicit in free speech doctrine because she challenges the account of the self on which it is based.

Nevertheless, there has always been another conception of freedom of speech-equally rooted in the Enlightenment project-that does not make the same binary assumptions about the autonomy or dependence of the self. This model assumes that selves are produced in part by the culture and institutions in which they live. It regards expression and access to knowledge as crucially important to the flourishing of culturally constructed selves. It argues that selves develop within a constantly changing culture that these selves, in turn, contribute to.

This model of free expression is premised on four interlocking ideas.

First, speech is about processes of persuasion - which may appeal to reasons, emotions, judgments, or values.

Second, the processes of communication result in mutual influence-people shape each others' values and opinions through participation in public discourse, including not only science and politics, but also art and popular culture.

Third, a crucial element of free processes of communication is the protection and accommodation of cultural and political dissent - through which people object to accepted conventions and social meanings, and to forms of power and status that affect them and others. Dissenters may challenge conventions as much as they challenge government officials; they may seek to reform cultural practices as much as laws; they may contest the power of culture as much as the power of the state.

Fourth, protection of freedom of speech protects cultural participation-because it is through participation that people produce, reproduce or alter conventions, understandings, and social practices.

These ideas of persuasion, mutual influence, dissent and cultural participation make particular sense from the standpoint of Cohen's portrait of the postmodern self. Selves are works in progress, borrowing from and copying others,

\footnotetext{
${ }^{24}$ Cohen v. California, 403 U.S. 15, 21 (1971).

${ }^{25}$ See Robert C. Post, Subsidized Speech, 106 YALE L. J. 151, 163 (1996) ("Ultimately, speech will be assigned to public discourse on the basis of normative and ascriptive judgments as to whether particular speakers in particular contexts should constitutionally be regarded as autonomous participants in the ongoing process of democratic self-governance.")
} 
renegotiating boundaries, following fads or rejecting them, and participating in cultural practices and conventions.

Moreover, culture is a form of power, perhaps even more pervasive and universal than political power. This power can be helpful or harmful, and it can promote human flourishing or undermine it.

Culture creates both problems and opportunities for human flourishing and human freedom. It both undergirds flourishing and freedom and threatens them. Culture gives us identities and limits on our identities; it promotes creativity and hinders our imaginations; it fosters our development and crushes us under the weight of conventions, genres, norms, and expectations.

If people are constructed in the way that Cohen says they are, how can people flourish within culture and not merely be subservient to it? How can people have a say in the forms of social power that constitute them as individuals and that shape the possibilities of their lives? They do this through their participation in the reproduction of social practices and through variation in these forms of reproduction. Put differently, people engage with forms of cultural power in part through what Cohen calls "play."

It is important not to overstate the importance of play. Not everyone is a cultural rebel, and not everyone's participation or variation in social undertstandings or practices is of equal effect. Most people's effects on culture are small or occur only at the margins. Yet it is the sum of these acts of cultural reproduction that keep culture-and cultural power-going over time. And because these forms of power limit individuals, foster individuals, shape identities, and create and constrain opportunities for different kinds of lives, the ability to hold this power to account, to vary it, to reshape its reproduction over time, is important.

Acts of cultural reproduction and participation in existing conventions always carry the possibility of their own variation. Jacques Derrida famously announced that "interability alters." ${ }^{26}$ The very repetition of the acts, practices and conventions that keep social meanings alive also creates the potential for their alteration and evolution. Culture in this sense is both always old and always new, because it is always being reproduced through individual interactions that are never quite the same as previous ones, and that are always being placed in new contexts. Some of this variation is unconscious; some is deliberate. Some is accidental; some is motivated. All of it contributes to cultural evolution over time, for good and for ill.

Therefore, play is important not simply from the perspective of the individual actor seeking freedom, but also from the perspective of cultural systems and the various assemblages of cultural power. Systems of cultural power depend on continual reproduction through the actions, thoughts and expressions of many different individuals in different social roles. The right of free

\footnotetext{
${ }^{26}$ Jacques Derrida, Limited, Inc. 62 (1988).
} 
expression gives individuals the ability to say yes, no-or equally importantly, "yes, but"-within the practices that reproduce cultural power. Cultures breed subcultures, ideas go viral, customs mutate, and conventions adapt.

What Cohen calls "play" has both individual and systemic aspects: there is play as individual experimentation or improvisation and there is play in the joints of cultural structures. Cultural participation is surely important to the growth and development of individual human beings; but it may equally be important from a collective standpoint because of its consequences for the reproduction of systems of cultural power. The potential for variation through play, mutual influence, persuasion and dissent creates the possibility of a different culture than the one in which we are now situated, and thus the possibility of different kinds of power and freedom, and thus different kinds of selves. Such change may bring human flourishing or its opposite, but the point is that cultural participation creates the opportunity for cultural change.

I have called this idea of individual cultural participation that helps reshape the culture one lives in "democratic culture." 27 Freedom of expression plays an important role in the promotion of such a culture, although, to be sure, it is only one aspect of a democratic culture. Free expression gives people a say about the forms of power that constitute them as individuals, and that, through cultural reproduction, foster, limit, constrain, and enable them. A democratic culture is not democratic because people hold a vote on what will be in or out of culture, but because everyone gets to participate in it, and through participating in it, they participate in its reproduction, and, equally important, its variation.

Many theories of free expression are grounded in a narrower conception of democracy. Their concern is the democratic legitimacy of the state. We should protect freedom of speech and the formation of public opinion because they facilitate democratic self-government or because they are necessary to the political legitimacy of a democratic state. The theory of democratic culture agrees that the democratic accountability of the state is important, but views it as part of a larger concern: providing democratic constraints on power over individuals generally.

There are many forms of power that affect individuals' lives beyond the state; they arise in the realms of morality, sexuality, economics, science, knowledge production, technological design, ideology, and convention. The fight for gay rights, for example, was not simply an attempt to change the law, although that was an important element. It was also an attempt to reshape understandings about sexuality in morality, in science, and in everyday social interactions; it was an attempt to reinterpret and reconfigure a wide range of cultural practices linked to sexuality. Moreover, even if we concern ourselves solely with political

\footnotetext{
${ }^{27}$ Jack M. Balkin, Digital Speech and Democratic Culture: A Theory of Freedom of Expression for the Information Society, 79 N.Y.U. L. Rev. 1 (2005).
} 
power, many forms of political power exist outside the nation state, in transnational social movements and in international politics. And as the example of the Internet demonstrates, many forms of technological and cultural power transcend the nation state, even as nation states attempt to control and domesticate them.

To be sure, there is a great deal more to culture than freedom of expression. And therefore a democratic culture is not guaranteed merely by freedom of speech. But the formation of public opinion, and the expression of ideas about conventions, morals, art, politics, and religion play important roles in the reproduction and evolution of culture. The protection of expression is therefore crucial to the realization of a democratic culture whatever else is also required.

Cohen's view of selves and her idea of freedom as play are broadly consistent with the idea that the purpose of free expression is to promote a democratic culture. To be sure, there is more to a democratic culture than play; conversely, there is more to Cohen's idea of the play of everyday practice than democratic participation in culture. Yet even if the concepts differ in important ways, there is still considerable overlap. Play gives people a space to vary and alter culture, and, to some extent, a say in the forms of cultural power that constitute them. Equally important, the promotion of freedom within a democratic culture does not presuppose the sort of fully autonomous selves that Cohen criticizes. Selves are in conversation with others and they are always being influenced by others. The ongoing negotiation of boundaries between self and others, and the development of selves within evolving culture is part of the process of mutual influence and cultural dissent, and therefore part of democratic culture.

Can we draw similar connections between freedom of speech and Cohen's idea of semantic discontinuity? If effective play requires semantic discontinuity, and if the promotion of a democratic culture through free expression requires the protection of play, then both free expression and a democratic culture require some kinds of semantic discontinuity. But what would this mean in practice?

First, think about limitations on intermediary liability. If the state tells intermediaries that they will be held liable if they do not search for, block, and remove illegal or tortious content, intermediaries will censor too much in order to play it safe. This phenomenon is called "collateral censorship:" 28 the state aims at intermediary $\mathrm{A}$ to get at speaker B, who may be anonymous. If A and B are not the same entity, A has reduced incentives to protect B's rights, and therefore will overcensor.

${ }^{28}$ See Jack M. Balkin, Virtual Liberty: Freedom to Design and Freedom to Play in Virtual Worlds, 90 VA. L. Rev. 2043, 2095-97 (2004); J. M. Balkin, Free Speech and Hostile Environments, 99 Colum. L. Rev. 2295, 2296-305 (1999); Michael I. Meyerson, Authors, Editors, and Uncommon Carriers: Identifying the "Speaker" Within the New Media, 71 Notre Dame L. Rev. 79, 116, 118 (1995). 
In contrast, safe harbor rules like section 512 of the Digital Millennium Copyright Act or intermediary immunities like Section 230 of the 1996 Telecommunications Act give intermediaries fewer incentives to block or censor content. These rules make it more difficult to punish tortious or illegal content, especially when the posters are anonymous. At the same time, immunities and safe harbors make possible a wide range of intermediaries and platforms that facilitate-or in some cases, promote-end user expression and user-generated content.

Intermediary immunities and safe harbors create discontinuities in digital enforcement regimes. The most efficient method for preventing dissemination of illegal or tortious content is to place liability on the cheapest cost avoider, who is often the intermediary. Intermediaries, for example, can install filtering systems to block or remove illegal content; sometimes intermediaries can identify the end users who send or upload it. Safe harbors and immunities remove intermediaries' responsibility for the content that flows through them, thus making it harder to enforce content controls.

At the same time, intermediary immunities show how semantic discontinuity can benefit powerful entities even more than ordinary individuals. Section 230 of the Telecom Act also holds intermediaries harmless if they decide to block or censor content. ${ }^{29}$ Section 512 of the Digital Millennium Copyright Act, which creates a safe harbor from liability, still allows YouTube to install filtering systems through deals with corporate content providers. Indeed, the real issue in the current litigation between Viacom and YouTube ${ }^{30}$ over the correct interpretation of section 512 is not whether end-users will be protected from content filtering. Rather, it is over what kinds of filters YouTube will install and who will pay for the service.

A second important aspect of semantic discontinuity in free speech law is the rule against prior restraints. Law students are often puzzled why the traditional common-law principle against prior restraints protects free expression if tort and criminal law allow for prosecution after publication. The answer is that the rule is an ancient form of semantic discontinuity. In comparison to a system of prior restraints, a system of subsequent punishments, even a relatively harsh one, creates multiple gaps in enforcement of the laws that restrict speech.

A prior restraint is a licensing system, in which a censor (either the state or a private party) decides whether speech will be permitted at all. Subsequent punishment is a system of prosecutorial discretion, in which the state or a

\footnotetext{
${ }^{29}$ See 47 U.S.C. 230 (c)(2) ("No provider or user of an interactive computer service shall be held liable on account of - (A) any action voluntarily taken in good faith to restrict access to or availability of material that the provider or user considers to be obscene, lewd, lascivious, filthy, excessively violent, harassing, or otherwise objectionable, whether or not such material is constitutionally protected; or (B) any action taken to enable or make available to information content providers or others the technical means to restrict access to material described in paragraph (1).”).

${ }^{30}$ Viacom, International, Inc. v. YouTube, Inc., 676 F. 3d 19 (2d Cir. 2012).
} 
private plaintiff decides whether it is worth undertaking the costs of prosecution or litigation.

Systems of prior restraint create bottlenecks with fewer procedural protections. They place the burden on the speaker to gain permission, and therefore the power of inertia rests with the censor, who may delay or simply decide against publication as a matter of administrative convenience. Having to ask permission alerts the censor to what is being published and establishes the idea of censorship as a norm. Moreover, if a speaker does not seek permission or tries to route around the system, retribution is likely because the speaker has specifically defied the authority of the censor. ${ }^{31}$

Systems of subsequent prosecution normally offer speakers a wide range of procedural protections, especially in criminal prosecutions. They allow publication without first seeking permission; therefore, the power of inertia rests with the speaker, not the state. Unlike a system of prior restraints, a system of subsequent punishments may not draw attention to the authorities about what is to be published, or identify the speaker in advance. Punishment is also less likely, because even if the expression is technically illegal under substantive law, the state or private parties must still decide whether the benefits of prosecution outweigh the costs.

The rule against prior restraints in the analog world is an example of semantic discontinuity because the burdens of cost and inertia are placed on the side of the speaker. Thus, a legal system that, on paper, is not very speech protective might nevertheless offer opportunities for freedom of expression in practice. Indeed, this seems to be what happened in the colonial and revolutionary period leading up to the ratification of the First Amendment in 1791. The law "on the books," inherited from the English common law, was decidedly unfriendly to free speech protection; but actual practices were far more libertarian. ${ }^{32}$ A combination of political culture, the jury system, and the costs of locating and prosecuting dissenters created cultural practices of free expression that were eventually translated into a constitutional guarantee.

The problems of prior restraint are exacerbated in a digital world. The dream of perfect enforcement comes closer to reality. The most efficient way of dealing with threats is ex ante, through blocking and filtering regimes, or through denying access to key elements of the networked infrastructure.

Filtering and blocking systems operate like prior restraints because instead of adjudicating the legality of speech after the fact, the government or

\footnotetext{
${ }^{31}$ For the classic discussion of the problems created by licensing systems for speech, see Thomas Emerson, The Doctrine of Prior Restraint, 20 Law \& Contemp. Probs. 648, 656-60 (1955).

32 See Leonard W. Levy, Emergence of a Free Press (1985) (rev. ed. of Leonard W. Levy, Legacy of Suppression (1960)); David A. Anderson, Levy vs. Levy, 84 Mich. L. Rev. 777 (1986); David M. Rabban, The Ahistorical Historian: Leonard Levy on Freedom of Expression in Early American History, 37 STAN. L. Rev. 795 (1985); David A. Anderson, The Origins of the Press Clause, 30 UCLA L. Rev. 455 (1983).
} 
intermediaries - or the two acting in concert - simply prevent it from flowing through digital networks. Permission to speak is granted or denied automatically, without human intervention. The criteria for blocking and filtering-or even the fact of filtering - may be hidden from end users, violating Cohen's goal of operational transparency.

Blocking and filtering regimes literally frustrate access to knowledge. Many of the problems of analog systems of prior restraint are amplified. The burdens of cost and inertia favor the censor, who need only change a few lines of code or flip a switch to block expression.

In a digital world that may not respect borders and is filled with anonymous actors, governments may find it better to nip problems in the bud rather than to try to locate and prosecute people after harm has occurred. And to nip problems in the bud, it is easiest to control the infrastructure. To this end, governments can aim at many different points of control: telecommunications companies, Internet service providers, search engines, online service providers and platform operators, domain name registrars and registries, and even support systems like web hosting services, advertisers, and financial payment systems.

Cohen's idea of semantic discontinuity is useful precisely because government and industry are increasingly adopting strategies of surveillance, filtering, and ex ante prevention. Governments increasingly seek to exploit points of control in the information infrastructure to achieve their policy goals. Cohen's book serves as an important reminder that the quest for perfect systems of enforcement can have consequences that are quite imperfect, especially where issues of cultural freedom - and, I would add, freedom of expressionare at stake.

\section{Conclusion: semantic discontinuity for me but not for thee}

Many of the issues of privacy and intellectual property that Cohen is concerned with in her book may be recast as issues of national security, terrorism, or crime prevention. This is perhaps the greatest difficulty for her approach. Once an issue is successfully characterized in public debates as a matter of national security, calls for imperfect, gap-filled systems may seem unrealistic and counterproductive. Governments face shadowy threats from overseas and can ill afford leaky systems of surveillance and enforcement. Not surprisingly, both governments and businesses that seek to protect intellectual property rights and rights of data collection have incentives to describe problems of governance in precisely these ways. What Cohen celebrates as semantic discontinuity they will see as imperfection and an obstacle to effective law enforcement rather than a strategy for protecting human flourishing. 
Nevertheless, at the same time, these governments and businesses will want to maintain their own form of semantic discontinuity. They will want to preserve for themselves plenty of room for maneuver and avoid surveillance of their own operations, while reducing or eliminating semantic discontinuity that benefits ordinary individuals. Indeed, this seems to be the general direction of digital enforcement-toward the construction of a great two-way mirror in which ordinary people's lives are increasingly transparent to powerful public and private entities that are not transparent to the people they view. Whether these developments are inevitable, or whether there is another, more democratic future available to us, is the great question for information policy in the digital age. 